\title{
Um livro didático de inglês e a representação de pessoas negras: desenhando uma abordagem de ensino-aprendizagem crítica
}

\author{
An English textbook and the representation of black people: designing a critical \\ teaching-learning approach.
}

Isabel Cristina Rangel Moraes Bezerra*

Universidade do Estado do Rio de Janeiro

Rio de Janeiro, Rio de Janeiro, Brasil

Ana Beatriz Cardoso do Nascimento**

Universidade do Estado do Rio de Janeiro

Rio de Janeiro, Rio de Janeiro, Brasil

Wellerson da Silva Ferreira*** Universidade do Estado do Rio de Janeiro Rio de Janeiro, Rio de Janeiro, Brasil

\begin{abstract}
Resumo: Nesse artigo, trazemos uma contribuição para a área que pesquisa a representação de pessoas negras em livros didáticos ao analisarmos um livro didático utilizado para o ensino de língua inglesa e propomos uma abordagem crítica para o ensino desse idioma. Trata-se de um recorte de pesquisa que se funda nos princípios da Prática Exploratória (MILLER, 2010, 2013) e que trata da formação inicial e continuada do professor de inglês. Esse movimento de olhar com mais cuidado alguns livros didáticos de inglês surgiu como demanda de dois professores em formação inicial, bolsistas de iniciação científica da pesquisa em questão. A arquitetura teórica desse artigo articula alguns estudos que fazem um resgate histórico da representação do negro em livros didáticos de algumas disciplinas escolares (RATTS; RODRIGUES; VILELA; CIRQUEIRA, 2006/2007; ROSEMBERG, BAZILLI, SILVA, 2003) e de língua inglesa, em particular, (FERREIRA; CAMARGO, 2013; FERREIRA, 2014). Trazemos contribuições dos campos da construção de identidade (MOITA LOPES, 2003) do letramento crítico (JANKS, 2012) e do letramento visual (BAMFORD, 2009).
\end{abstract}

Palavras-chave: Prática Exploratória. Representação do negro. Letramento crítico. Livro didático de inglês. Ensino de inglês.

Abstract: In this article we bring some contribution to the research area that studies the representation of black people in textbooks. We analyze a volume of a textbook used to the teaching of English as a foreign language in municipal schools of Rio de Janeiro city. We also propose a critical approach to the teaching of this foreign language. This article presents part of the study that is being developed by the authors in a research project that follows the principled approach to teaching and research of Exploratory Practice. It focuses on the initial and in-service process of English language teacher education. The movement towards including this careful look at textbooks of English arose as part of the desire brought by two pre-service teachers who are scholarship holders in the above mentioned research project. The theoretical framework that underpins this research includes some studies that bring a historical overview on the representation of black people in textbooks designed for some school subjects (RATTS; RODRIGUES; VILELA;

* Doutora em Letras, professora da Universidade do Estado do Rio de Janeiro. Email: icmoraes@uol.com.br.

** Bolsista de Iniciação Científica/UERJ - Curso de Letras na Faculdade de Formação de Professores da Universidade do Estado do Rio de Janeiro - Brasil. E-mail: nabeatrizc.donascimento@hotmail.com *** olsista de Iniciação Científica/UERJ - Curso de Letras na Faculdade de Formação de Professores da Universidade do Estado do Rio de Janeiro - Brasil. E-mail: wellersoncontato@rocketmail.com 
CIRQUEIRA, 2006/2007; ROSEMBERG, BAZILLI, SILVA, 2003) in general, and English, in particular (FERREIRA; CAMARGO, 2013; FERREIRA, 2014). We also use contributions that come from the fields of identity (MOITA LOPES, 2003), critical literacy (JANKS, 2012), and visual literacy (BAMFORD, 2009).

Keywords: Exploratory Practice. Representation of black people. Critical literacy. Textbook. English teaching.

\section{PALAVRAS INICIAIS}

Ao estudarmos letramentos, identidade, formação do professor de inglês e ensino de língua inglesa no projeto de iniciação científica que nos une e que é construído a partir da abordagem para a formação docente, para o ensino e a pesquisa da Prática Exploratória (ALLWRIGHT; HANKS, 2009; MILLER, 2010, 2013), nos deparamos com a possibilidade de refletir sobre a presença de pessoas negras no livro didático de língua inglesa. Na verdade, tal movimento veio dos bolsistas de iniciação científica, que trouxeram para a universidade sua vivência de alunos e cidadãos negros, articulando sua demanda de trabalhar para entender questões referentes ao negro na escola, na universidade e no livro didático ao projeto de pesquisa. À medida que a pesquisa se desenvolvia e trabalhando para entender o ensinoaprendizagem de língua inglesa envolvendo narrativas de professores em formação, os bolsistas, coautores desse artigo, começaram a apontar a invisibilidade da figura do negro - professor, personagens de livros didáticos - nos espaços escolares pelos quais haviam transitado. Assim, em colaboração com a professora orientadora, direcionaram a questão do ensino-aprendizagem de inglês e da formação docente para a reflexão sobre a representação de pessoas negras em livros didáticos e, igualmente, sobre a formação do professor de inglês negro.

Como parte dos estudos que desenvolvemos no projeto de pesquisa, trazemos esse recorte que busca mapear a presença (ou não) da figura da pessoa negra em um livro didático [LD] para o ensino de língua estrangeira [LE]/ língua inglesa [LT]. Essa obra integra uma coleção que foi adotada pela Secretaria de Educação do município do Rio de Janeiro e usada em escolas do ensino fundamental II. No entanto, não nos limitamos a isso. Trazemos uma reflexão sobre a possibilidade de se desenhar e construir uma prática docente reflexiva, fundada na Prática Exploratória e no letramento crítico. Como já apontado, a arquitetura teórica do estudo articula, de forma breve, alguns estudos que fazem um resgate histórico da representação do negro em livros didáticos de algumas disciplinas escolares (RATTS et al., 2007; ROSEMBERG, BAZILLI, SILVA, 2003; SANTOS, 2011) e de língua inglesa, em particular (FERREIRA; CAMARGO, 2013). Para construir nossa análise e apontar uma possibilidade de prática docente, trazemos reflexões dos campos do letramento crítico (JANKS, 2012, LANKSHEAR, 2002) e do letramento visual (BAMFORD, 2009), assim como da Prática Exploratória (ALLWRIGHT; HANKS, 2009; MILLER, 2010).

\section{REPRESENTAÇÃO DO NEGRO E PRECONCEITO EM LIVROS DIDÁTICOS}

De acordo com Ratts, Rodrigues, Vilela e Cirqueira (2006/2007), a história dos negros no Brasil, é profundamente marcada pelo racismo que se reflete, de maneira mais ou menos 
explícita, em muitas publicações voltadas para o ensino-aprendizagem de diversas disciplinas no ensino fundamental. Negrão (1988) aponta em suas pesquisas que o pioneiro a tratar sobre essas questões no Brasil foi o professor e filósofo da USP, Dante Moreira Leite, que, em 1950, publica no Boletim 3 de Psicologia da Faculdade de Filosofia, Ciências e Letras da USP o artigo intitulado "Preconceito Racial e Patriotismo em Seis Livros Didáticos Primários Brasileiros" (LEITE,1950). Nele, o autor analisa livros didáticos adotados desde o final do século XIX até os anos 1940, explicitando o preconceito racial nesses livros. Leite (1950, p. 211 apud NEGRÃO, 1988, p.53) afirma que os livros didáticos criam "uma realidade adaptada ao ideal que o escritor pretende incutir em seus leitores". A partir disso, ele mapeia forma como o preconceito se apresenta em seis livros didáticos. Negrão (1988, p. 53) resume os itens listados por Leite nesse mapeamento e nós os apresentamos a seguir:

a não representação de personagens negros na sociedade descrita nos livros; a representação do negro em situação social inferior à do branco; o tratamento da personagem negra com uma postura de desprezo; a visão do negro como alguém digno de piedade; o enfoque da raça branca como sendo a mais bela e a de mais poderosa inteligência; o combate ao preconceito através de exemplos da História do Brasil.

Mencionando a pesquisa de Bazzanella que, em 1957, analisou dez livros de leitura, Negrão (1988) aponta que o autor chegou à conclusão que a ocorrência de estereótipos explícitos era pequena, mas verificou que o negro era colocado em posição subalterna. Em 1976, Rego analisa livros de Comunicação e Expressão - $3^{\mathrm{a}}$ e $4^{\mathrm{a}}$ séries do $1^{\mathrm{o}}$ grau - adotados em três municípios do Rio de Janeiro. Nessas obras, por exemplo, quando o tema pátria é abordado, o negro é mencionado, mas é trazido como personagem do passado histórico e não como atuante no momento presente. Pinto (1987) analisa a representação do negro em LD de leitura e verifica a coexistência de discursos igualitários com representações discriminatórias de personagens. Em sua análise das ilustrações, Pinto (ibid., p.88) assinala que

\footnotetext{
praticamente todos os itens indicadores de uma posição de destaque na ilustração privilegiam os personagens brancos. Eles são mais frequentes, desempenham a função de representantes da espécie [...], ocupam posição de proeminência nas ilustrações que retratam grupos de personagens e são os mais ilustrados nos locais privilegiados do livro. A pouca evidência de personagens negros e mestiços transparece na frequência muito baixa, na inexistência de grupos e multidões negras, bem como na quase ausência de personagens negros e mestiços ilustrados na capa ou ocupando posição proeminente na ilustração, quando em companhia dos outros.
}

A autora ainda menciona o tratamento estético diferenciado dado a personagens brancos, de um lado, e negros e mestiços, de outro, contribuindo para reforçar estereótipos e certas imagens associadas ao segundo grupo. Silva (2011) analisou a representação do negro no LD de língua portuguesa da década de 90 e verificou mudanças nas ilustrações que traziam personagens negros. Por exemplo, na maioria dos livros analisados, esses personagens não apresentavam aspectos caricaturais, possuíam nomes próprios, contexto familiar, tinham o status de classe 
média, não eram apresentados em papeis e funções considerados subalternos, havendo diversificação de papeis e funções. A autora verificou que

As crianças representadas negras vão à escola, têm amigos de outras raças/etnias e interagem com elas sem subalternidade. Praticam atividades de lazer. Não são apenas más, como outrora. Praticam travessuras e boas ações, são elogiadas e recebem adjetivação positiva por parte de adultos não negros. Foram localizadas em lugar de destaque em grande parte das ilustrações, tais como, no centro, em primeiro e segundo lugares.

No que tange o LD de língua inglesa, há, igualmente, investigações voltadas para o mesmo objetivo. É um movimento mais recente e tem forte representação no trabalho de Ferreira (FERREIRA, 2013, 2014; TEIDER; FERREIRA, 2011; FERREIRA; CAMARGO, 2014; FERREIRA, 2014; FERREIRA, 2012). Apoiada em outros pesquisadores, a autora (2014, p.97) afirma que, em LDs de língua estrangeira, "os homens brancos, heterossexuais e classe média têm maior visibilidade e prestígio". Remetendo o leitor a uma pesquisa desenvolvida por ela em 2012, Ferreira comenta a análise que fez a um livro didático de LI o qual alcançou o maior índice de vendas no Brasil. Nessa obra, "a pesquisa demonstrou [...] que havia 567 pessoas brancas representadas e 37 pessoas negras". A partir desse e de outros dados colocados em uma tabela que registra a representação de homens e mulheres brancos, asiáticos e negros na obra, a autora problematiza a questão do poder:

Quando nos deparamos agora com esse resultado para refletir sobre as questões de poder, não é difícil dizer qual é o grupo que tem maior poder de visibilidade, de acesso, de ser representado mais vezes em várias posições sociais no livro didático. E por causa dessa visibilidade e representação imensa da identidade racial branca, ideologia do branqueamento, o poder simbólico de ser branco é evidente (FERREIRA, 2014, p.98).

Ao discutirem o racismo cordial em LD de inglês aprovado pelo PNLD de 2011, Ferreira e Camargo (2014) verificaram que o negro ainda foi representado de forma estereotipada, sendo bom em esportes (atletas famosos), música e cinema (atores norte-americanos). Por isso, "a branquitude normativa e as personagens negras em profissões estereotipadas ratificam a complexidade e o racismo velado, em trazer negros com profissões pouco valorizadas e relacionadas à sorte, dom ou esporte" (FERREIRA; CAMARGO, 2014, p. 188).

Oriá (1996), que igualmente problematizou a representação do negro em LDs, afirmou que o mesmo "não é neutro, imparcial, mas sim portador de uma ideologia - ideologia esta que, muitas vezes, reproduz os conceitos e valores dos setores dominantes da sociedade" (1996, p.155). Rosemberg, Bazzilli e Silva (2003), discutindo sobre o racismo em LDs e seu combate no Brasil, fazem uma análise de alguns documentos que traziam parâmetros para o combate à xenofobia e para a escolha de LDs. Para esses autores, é com o Programa Nacional do Livro Didático [PNLD], implantado em 1996, que há uma preocupação específica com componentes racistas nos livros didáticos. Inicialmente, o critério observado voltava-se para questões que se referissem a preconceitos de "origem, raça e cor", sendo modificados para "origem, cor e etnia" 
posteriormente. Os autores informam que nos PNLD de 97 e 98 afirmava-se que "os livros não podem expressar preconceitos de origem, raça, sexo, cor, idade e quaisquer outras formas de discriminação" (BRASIL, 2000). Já o decreto n 9.099, de julho de 2017, em seu artigo terceiro, inciso II, dispõe que, dentre as diretrizes do PNLD, está a de "respeito às diversidades sociais, culturais e regionais", não fazendo menção direta àqueles elementos. Ainda com relação ao PNLD, Jorge (2014, p.75), que participou da construção do edital de 2011, assevera que nesse edital

foram explicitadas as perspectivas de promoção positiva da imagem da mulher, dos negros e dos povos indígenas; a abordagem da temática de gênero; a promoção da educação e da cultura dos direitos humanos, principalmente no que se refere às crianças e adolescentes; da educação para a justiça social, antirracista e anti-homofóbicas.

A partir da problematização feita por Ferreira e Camargo (2014) acima sobre o livro avaliado para o PNLD de 2011 o qual, segundo as autoras, representava a pessoa negra ainda de forma estereotipada, em uma forma de racismo cordial, entendemos ser ainda preciso refletir sobre os processos de avaliação das coleções submetidas, assim como sobre a seleção daquelas que são apresentadas no Guia do PNLD ao final do processo. Certamente essa problematização não questiona a lisura do processo avaliativo, mas a forma como os avaliadores são capacitados para entender as indicações do edital, bem como os critérios ou descritores da ficha de avaliação. Isso porque se espera "pelas orientações e aplicações dos documentos oficiais em sala, a quebra das noções de verdade que foram ensinadas ao longo dos anos nas escolas, principalmente no que diz respeito ao sujeito negro e ao processo de colonização no Brasil" (FERREIRA; CAMARGO, 2014, p.181).

Uma vez que o LD de LE, em particular o de língua inglesa, foi incluído no conjunto de coleções oferecidas gratuitamente aos professores de escolas públicas a partir de 2011 com o PNLD, a relevância de pesquisas sobre esse material ainda se faz não apenas com vistas à identificação de expressões de preconceito a diferentes etnias/raças, mas a diferenças de qualquer ordem.

\section{IDENTIDADE E LIVRO DIDÁTICO}

Ao trazermos a questão da identidade, sublinhamos que não a entendemos como monolítica, una e acabada. Alinhamo-nos aos teóricos da área que a veem como dinâmica, processual, múltipla, contraditória. Portanto, embora estejamos tratando da representação do negro em um livro didático e as possíveis implicações para o processo de construção identitária dos aprendizes, entendemos que outras questões perpassam a identidade do negro, indo além da raça/etnia, abarcando gênero, status social, faixa etária, por exemplo. Para Moita Lopes (2003), estas implicações na construção da identidade estão sujeitas a uma série de interferências de ordem social, política, tecnológica. Não está relacionada à subjetividade interior do indivíduo, mas aos processos sociais que acontecem entre as pessoas (SHOTTER, 1989, p. 137). Partindo 
do pressuposto que essa construção se dá através do outro, não sendo um processo individual, mas como construções sociais e, portanto, discursivas, "aprendemos a ser quem somos nos encontros interacionais de todo dia" (MOITA LOPES, 2003, p. 16).

Considerando nosso foco, tomamos o livro didático como elemento que também concorre para os processos discursivos de construção identitária dos usuários - alunos e professores. Ferreira e Ferreira (2011, p. 117) lembram que "a construção de identidade social de raça/etnia na escola perpassa pelos materiais de ensino utilizados em sala de aula". Conforme Ferreira e Camargo (2013, p. 180), "o aluno negro, ao se deparar com a imagem dos negros estereotipados nos materiais didáticos, sofre um flagelo na sua formação identitária”. Assim sendo, a baixa representatividade das pessoas negras nos livros escolares que tem sido informada por pesquisadores como Ferreira (2014) tem implicações para a construção da identidade dos aprendizes, negros ou não. Por outro lado, quando há representatividade maior ou equilibrada, é preciso verificar como ela se concretiza na forma como textos e imagens posicionam as pessoas negras, 'se' e 'como' reflexões sobre essa representatividade têm espaço na obra.

Fazemos essas colocações porque, apoiados em Shotter (1989:137 apud MOITA LOPES, 2003), não relacionamos identidade à subjetividade interior dos aprendizes, mas "a processos sociais que acontecem entre as pessoas". Partimos do entendimento que essa construção se dá através do outro em práticas discursivas. Como indica Parker (1989, p. 56 apud MOITA LOPES, 2003) "o si-mesmo é construído em discursos e a seguir re-experienciado dentro dos textos da vida cotidiana". Assim, o LD, que vai ser ponto de partida para interações em sala de aula, tem um papel relevante pelos textos que traz, pelas ilustrações e atividades propostas. Somos atravessados pelos discursos que circulam socialmente, veiculados nos textos de diversos gêneros, construindo-nos identitariamente; consequentemente, os discursos veiculados nos LDs também o fazem. Por isso, é preciso uma abordagem de ensino aberta às histórias e vida dos aprendizes, sensível ao contexto. Uma abordagem que envolva os aprendizes para construírem uma leitura crítica e reflexiva de textos e de imagens dos LDs. Um movimento no sentido de juntos, professores e alunos, no espaço discursivo de suas salas de aula, desconstruírem preconceitos, (re)construírem-se identitariamente, visando a construção de inteligibilidade sobre o mundo social para a construção de sociabilidades fundadas no respeito às diferenças de toda ordem.

\section{A CONSTRUÇÃO DE UM ESPAÇO EXPLORATÓRIO DE CONSTRUÇÃO DE CONHECIMENTOS COM O LETRAMENTO CRÍTICO}

Tratando de Linguística Aplicada, área em que as questões tratadas nesse artigo se inserem, Rajagopalan (2011, p.76), em uma entrevista, afirma que "temos que voltar nossos pensamentos para o mundo que estamos vendo, vivendo". Mais adiante, ao ser questionado sobre a tendência de se estender o ensino de língua inglesa para faixas etárias de aprendizes cada vez menores, ele responde que "o ensino de língua não é brincadeira”, dada as questões ideológicas, políticas e geopolíticas envolvidas. Entendemos que as duas afirmações devem ser trazidas para a questão em tela do presente artigo. 
As discussões levantadas nas seções anteriores necessariamente apontam para a o ensino de LE, da prática docente que se concretiza em sala de aula. Sem fazer incursão aprofundada na área de formação inicial e continuada do professor de línguas, posto que abordaremos essa questão em outro texto, de início percebemos ser essa uma questão nodal. Se discussões sobre aspectos multiculturais não fizerem parte da reflexão nesse processo, se não houver embasamento teórico advindo de pesquisas para fundamentar tais discussões e, sobretudo, se os professores em formação não forem ouvidos, notadamente os professores negros, não há como construir uma prática transformadora. Ainda na entrevista, Rajagopalan (2011, p. 80) defende que "um professor na sala de aula tem a necessidade de atuar politicamente, sim. É seu dever enquanto cidadão atuar politicamente e inclusive pensar a respeito de como a língua deve ser, qual o lugar que a língua estrangeira deve ocupar na política geral'". Essa fala de algum modo reforça as questões que trazemos sobre a formação do professor para tratar de questões raciais/étnicas no contexto de ensino de línguas e de uso do livro didático, uma vez que esse profissional estará, segundo nossa perspectiva, assumindo um lugar político. Jorge (2014) alerta para o fato de que a formação de professores de LE parte do pressuposto de que a aprendizagem de LE assenta-se em uma perspectiva multicultural. Apoiada em Kubota (2004), a autora assinala que o ensino de LE é "afetado pelo multiculturalismo liberal, eurocêntrico e cego às diferenças, com discursos que perpetuam hierarquias linguísticas e culturais" (JORGE, 2014, p.83). Além disso, Ferreira (2014, p.108) aponta que "muito mais tempo deve ser dedicado à formação de professores para que eles façam as escolhas mais adequadas dos livros didáticos para seus alunos".

Miller (2013, p. 105), posicionando-se como professora formadora a partir da abordagem ético-inclusiva da Prática Exploratória, verifica que tem havido um afastamento crescente do paradigma da racionalidade técnica em contextos acadêmicos de formação de professores onde circulam novas teorizações. Nesse sentido, a Prática Exploratória vem contribuir para a instauração de práticas docentes reflexivas, inclusivas, sensíveis ao contexto [institucional] e às demandas trazidas pelos aprendizes - as demandas que afetam a qualidade de vida em sala de aula e fora dela, envolvendo crenças, emoções, narrativas de experiências e de tristes realidades.

Nesse quadro, os praticantes exploratórios constroem colaborativamente suas reflexões sobre questões de vida trazidas para o espaço-tempo escolar, a partir de uma perspectiva de geração de entendimentos situados, não generalizáveis, que os ajudem a entender aspectos diferentes, complexos e multifacetados das questões levantadas. Isso pode ser feito através de puzzles (questões a entender) que lhes ajudem a agir construindo relações interpessoais mais solidárias. Não estamos falando de mudanças em práticas de ensinar-aprender cotidianas para resolver problemas detectados, uma vez que "esta busca reflexiva [...] se contrapõe à tendência racionalista pela resolução de problemas inspirada em modelos tecnicistas que valorizam a eficiência" (Miller, 2010, p.116). Esse é um ponto relevante considerando que nosso foco é a configuração de uma pedagogia exploratória e crítica que integre ensino e reflexão, envolvendo todos na sala de aula como forma de contribuir para debates de questões da contemporaneidade como preconceitos, racismos, uso de tecnologia, diferenças e diferentes, por exemplo. 
Para entender a Prática Exploratória, precisamos atentar ao fato de que ela não pode ser considerada como um método pronto e com regras a serem seguidas em sala de aula. De acordo com Miller, em uma entrevista concedida ao periódico Educação Pública (CRUZ, 2007), podemos definir a Prática Exploratória como uma forma de ensinar e aprender. Ela é uma forma de estar em sala de aula que permite expandir aquilo que se sabe, bem como construir uma atitude ativa e curiosa em relação a questões que nos mobilizam, que nos afligem ou incomodam, que nos movem emocionalmente, intelectualmente, socialmente. Ao ser questionada por Cruz se a Prática Exploratória sempre partia de perguntas, Miller responde com base em sua experiência com professores em formação inicial e continuada:

As questões são a forma que faz com que essa postura de ficar em sala de aula se torne mais clara. Muitas vezes os professores que participam das nossas oficinas, ao começarem a entender um pouco da Prática, pensam que estamos fazendo filosofia, talvez devido a essa aceitação da incerteza. Um grande diferencial da Prática Exploratória é que ela não veio trazer soluções, nem verdades, não diz “faça assim!" É sempre a partir da pessoa, dando valor às questões das pessoas. É muito legal e fascinante ver as questões que os alunos têm, de tudo quando é tipo; assim, cada aula é diferente. $\mathrm{O}$ caminho que uma pergunta com o "por quê" traça é diferente de uma pergunta feita com o "como". "Por que os alunos não fazem dever de casa?" A partir daí vão vindo outros "por quês" e novos caminhos vão se abrindo. E a maneira de buscar as respostas são as mais variadas: o aluno vai conversar com os colegas, com outros professores, pesquisar. (MILLER in CRUZ, 2007)

Em oficinas como as citadas por Miller, em atividades de sala de aula, o trabalho de ensinar-aprender com base na abordagem da Prática Exploratória tem propiciado o surgimento de puzzles como os exemplos a seguir que foram produzidos por professores e por seus alunos, envolvendo situações de vida profissional/escolar e pessoal/familiar:

Por que temos que respeitar o professor"

Por que temos que fazer prova?

Por que precisamos ser amados?

Por que ensinamos aos alunos a terem uma atitude mais crítica ao que lhes é ensinado se ainda decidimos o que eles têm que aprender?

Por que meus alunos têm um tempo de atenção tão curto?

Por que ler para meu filho é uma batalha perdida?

Por que fazer passeios com meus alunos é tão importante?

Por que os homens agridem as mulheres?

Por que o ensino de inglês na escola pública ainda é tratado de maneira não-crítica?

Por que minhas aulas são tão legais?

Por que os alunos são tão ligados ao funk?

Por que os professores de história são contra nós?

Por que a mulher tem que ser o coração da família?

Por que muita gente tem preconceito contra idosos?

Por que minha religião não é respeitada aqui na escola?

Por que as pessoas não aceitam professores gays? 
Abaixo inserimos duas ilustrações de puzzles construídos por alunos e partilhados em pôsteres. A primeira apresenta o pu₹zle de dois bolsistas PIBIC, coautores desse artigo. Ele foi apresentado em um evento acadêmico do Instituto Superior Anísio Teixeira em São Gonçalo, Rio de Janeiro em 2016.

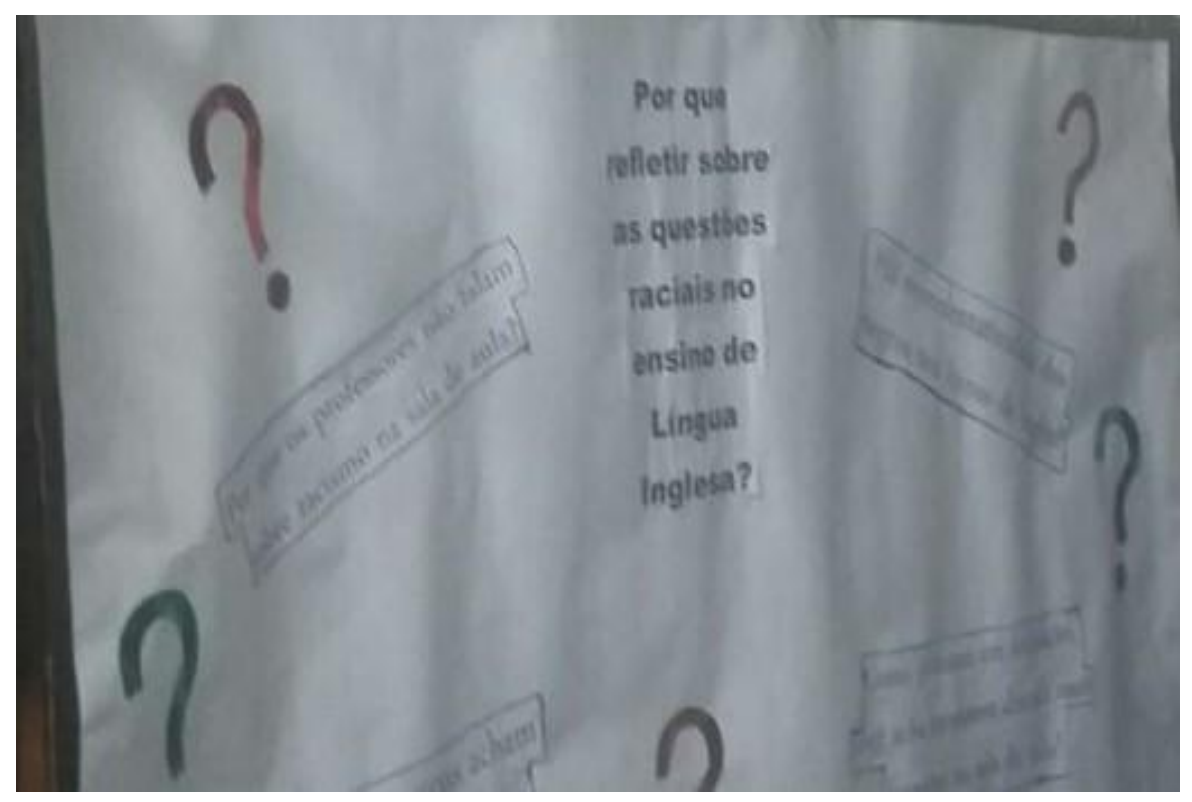

A segunda apresenta um pôster produzido em 2011 por duas alunas do Instituto de Educação Carlos Pasquale, situado no município de Nilópolis, Rio de Janeiro, durante as aulas de inglês ministradas por Moraes Bezerra, coautora desse artigo. Nessa escola é oferecido o curso Normal que objetiva formar professores para atuarem no Ensino Fundamental I. A escola atende a alunos vindos de várias escolas tanto municipais quanto particulares de Nilópolis e de municípios vizinhos. Muitos alunos nunca haviam estudado a língua inglesa ou tiveram aulas em algumas séries do Ensino Fundamental II (segundo segmento do Ensino Fundamental) seja por falta de professor, seja por haverem estudado espanhol ou francês. A partir de uma atividade de listening comprehension (nos termos da Prática Exploratória, uma Atividade Pedagógica com Potencial Exploratório [APPE] usada para integrar ensino-aprendizagem e reflexão) em que os alunos foram encorajados a proporem seus puzzles, elas, alunas negras, decidiram trabalhar para entender a questão do racismo. É preciso sublinhar que a produção do pôster pelos alunos contou com o auxílio da professora. Não obstante, ela respeitou a forma final da produção dos textos, como os alunos escreveram, porque eles haviam aceitado o desafio de produzirem algo em inglês e, para a grande maioria, essa era a primeira vez que escreviam na língua do 'outro', expressando seus próprios sentimentos, suas questões. 


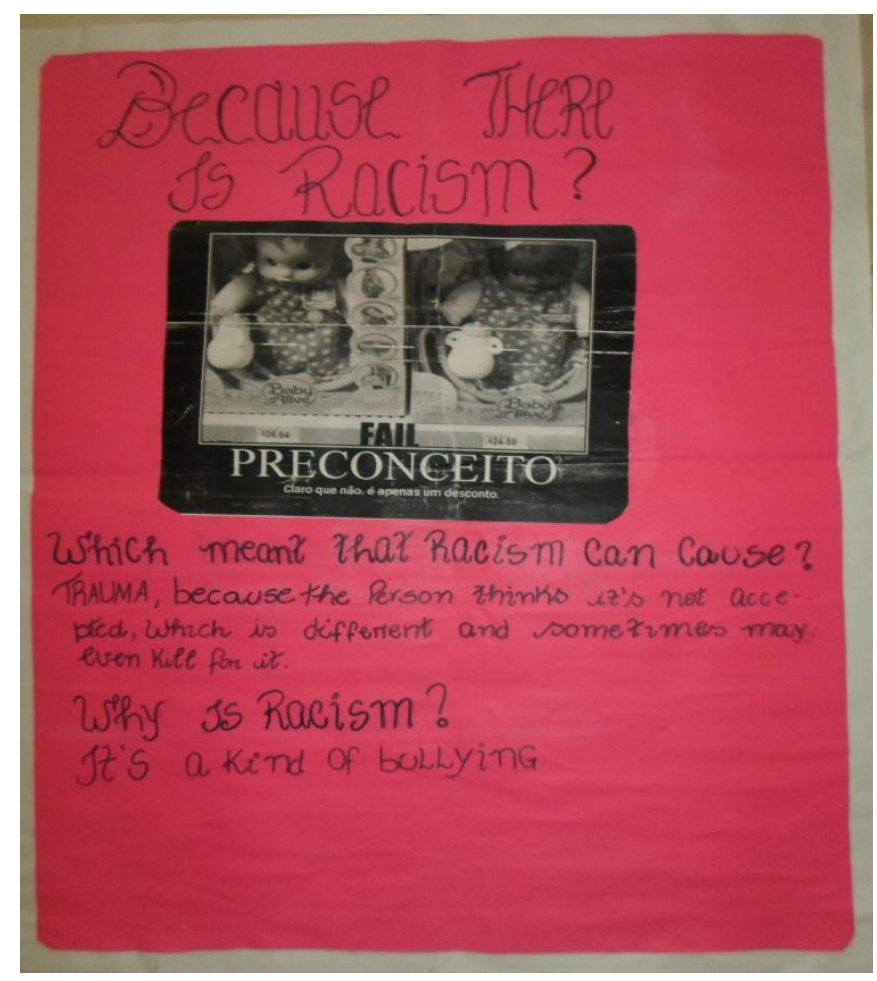

Esse exemplo de prática docente, bem como os de outros professores e professoras exploratórios, além de estar balizado pelos princípios que os ajudam a construir a ação integrada de ensinar-pesquisar-refletir, igualmente coaduna com as seguintes ideias sobre aprendizes, conforme proposto por Allwright \& Hanks (2009, p. 7). De acordo com esses autores, os aprendizes são pessoas únicas que aprendem e se desenvolvem melhor quando o fazem à sua maneira. Além disso, por serem seres sociais, eles aprendem e se desenvolvem melhor quando estão em um ambiente de apoio mútuo/ quando se apoiam entre si/ uns nos outros. Dessa forma, são capazes de levar seu aprendizado a sério e de tomar suas próprias decisões. São capazes de se desenvolverem como construtores do seu processo de aprendizagem.

Os puzzles e pôsteres acima nos permitem ver uma possibilidade de construir um diálogo entre a Prática Exploratória e a reflexão trazida pelas discussões sobre letramento crítico. Embora pudéssemos lançar mão de vários autores que discutem o letramento crítico, para a reflexão que aqui construímos um texto de Janks (2012), cuja citação encontra-se abaixo, mostra bem o espaço para tal alinhamento:

Em um mundo pacífico sem a ameaça de aquecimento global ou conflito ou guerra, onde todos têm acesso à educação, saúde, comida e uma vida digna, ainda haveria a necessidade do letramento crítico. Em um mundo que é rico com a diferença, ainda existe a possibilidade de haver intolerância e medo do outro. Devido ao fato de a diferença ser estruturada na relação de poder, o acesso desigual a recursos com base em gênero, raça, etnia, língua, habilidade, sexualidade, nacionalidade e classe 
continuarão a produzir privilégio e ressentimento. Mesmo em um mundo onde relações de poder socialmente construídas tenham sido minimizadas, ainda assim teremos que administrar as politicas de nossas vidas cotidianas. Tenho chamado essas políticas de políticas com 'p' para distingui-las de políticas com 'P'. (Janks, 2012, p. 150)

A autora sugere que, para efeito desse letramento, que operemos com 'critique' [embora a tradução seja 'crítica', manteremos a palavra original] para desconstruir e redesenhar (redesign) textos a fim de construir outras instâncias na micro-política da vida cotidiana - a política com 'p'. Janks (ibid.) sustenta que as escolhas de quem produz textos estão circunscritas a formas de pensar, acreditar e valorar inscritas nos discursos em que habitamos. Por isso, sem 'critique' a possibilidade de romper com esses discursos fica reduzida. É preciso um estranhamento que permita pensar em como o texto poderia ser diferente, lendo-o com e contra não apenas o conteúdo, mas também contra a forma, contra os interesses do texto. Só assim é possível redesenhá-lo. A autora ainda chama atenção para o fato de que tanto o desenho (design) quanto o redesenho (redesign) podem ser usados eticamente ou não para propagar os interesses de alguns à custa dos interesses dos outros. É a ideia do poder que circula conforme Foucault (1980), afirma Janks.

Como convenções de escrita, gêneros e a própria gramática sempre estiveram sujeitas à mudança, pela proposta de Janks, todos os textos estão abertos à reconstrução. Ela defende que através de 'critique" "a habilidade de entender que os discursos nos produzem, falam através de nós e podem, apesar disso, ser desafiados e modificados" (JANKS, 2012, p. 159). Essa forma de ler o texto é desafiadora e convida o leitor a sair de um lugar e pensar alternativas. Para Lankshear (2002, p. 44), o letramento crítico envolve potencialmente o conhecimento de letramento em geral, ou especificidades de letramento, criticamente. Colabora para que se tenha uma perspectiva crítica acerca de letramentos e de textos específicos. Encaminha para que se faça uma "leitura crítica" de práticas sociais, classificações, relações, apontamentos, procedimentos, etc.

Essas questões são fundamentais em aulas de línguas, em especial para a discussão que trazemos nesse artigo, pois remetem também a textos escolhidos para fazerem parte de LDs. Como o LD, além disso, traz ilustrações e fotos para dar suporte a textos e a atividades, consideramos ainda necessário trazer brevemente alguma elaboração sobre o letramento visual, conforme Bamford (2009) a ser articulado a essa perspectiva de 'critique' e redesign trazidas por Janks. Segundo Bamford (ibid., p.1), para que o leitor construa sentidos a partir de imagens, ele usa habilidades críticas de exploração, crítica e reflexão. Esse letramento é "uma forma cuidadosa e sustentável de compreensão e não está limitado a uma disciplina em particular ou a uma área do currículo. É algo que deve ser ensinado desde a infância e envolve a consideração inteligente de imagens de um grande numero de fontes" (BAMFORD, 2009, p.2). A autora sugere que usemos, por exemplo, as seguintes perguntas:

- Em que ponto da história e em que contexto a imagem foi criada?

- Quem encomendou a imagem?

- Para qual propósito a imagem foi criada? 
- Em que contexto a imagem foi vista?

- Quem é o público pretendido para ver a imagem?

- Em que forma de mídia a imagem é vista?

- O que foi omitido, alterado ou incluído na imagem?

- O que a imagem diz acerca da nossa história?

- O que a imagem comunica sobre a nossa identidade individual e social?

- O que a imagem diz sobre a sociedade?

- O que a imagem diz sobre um acontecimento?

- O que a imagem comunica sobre os aspectos culturais? (ibid., 2009, p.4)

Dentre as implicações para o ensino a partir da proposta de Bamford (2009, p.5), a autora aponta várias necessidades. Citamos aquelas que nos interessam mais especificamente para o diálogo que pretendemos estabelecer aqui. São elas: necessidade de estabelecer habilidades de pensamento crítico em relação a imagens; necessidade de aumentar as habilidades orais e escritas de letramento assim como de vocabulário para poder falar e escrever sobre imagens; necessidade de integrar o letramento visual em todas as áreas do currículo; necessidade de fazer perguntas aos alunos sobre imagens; necessidade de encorajar os alunos a olharem para pressupostos subjacentes que estejam imbricados em imagens que circundam os jovens; necessidade de encorajar os alunos a investigarem imagens criticamente, bem como a analisarem e julgarem os valores inerentemente contidos nas imagens.

\section{ANALISANDO O LIVRO DIDÁTICO E DESENHANDO UMA ABORDAGEM PARA O ENSINO}

Considerando-se que essa pesquisa se insere no campo da Linguística Aplicada e usa de uma abordagem qualitativa e interpretativista ao olhar que fazemos ao exemplar do livro didático que compõe uma coleção para o ensino de LI na rede pública municipal da cidade do Rio de Janeiro, os dados numéricos que trazemos relativos à ilustração fazem parte de uma quantificação obtida pela visualização das imagens na obra. Esses números servem de base para pensar a representação do negro, porém, o que mais tem peso no movimento analítico diz respeito à interpretação de como personagens negras são apresentadas e, considerando que acompanham textos e atividades, se os textos e atividades apresentam uma abordagem relacionada ao letramento crítico. Além disso, embora saibamos que a obra não tenha sido planejada a partir da abordagem proposta pela Prática Exploratória, tentaremos apontar, se possível, em uma das unidades do LD, momentos em que a ação docente poderia ser construída no sentido de envolver os aprendizes em um processo reflexivo sobre diversidade racial/étnica, multicultural.

O volume selecionado faz parte da coleção Interaction ED-4 (LAXE; BÜSMAYER, 2012), publicado pela Learning Factory, editora agregada a uma rede privada de institutos de ensino de inglês. Essa editora fornece livros e material de apoio para as escolas municipais e o objetivo é atender a um programa assumido pela prefeitura municipal em 2009. Tal programa visava o 
evento internacional que aconteceu no Rio de Janeiro em 2016: as Olimpíadas. Na página da secretaria de educação, encontramos a seguinte informação:

O programa Rio Criança Global, criado em 2009 pela Prefeitura do Rio, por meio da Secretaria Municipal de Educação, tem como objetivo intensificar e estender o ensino de inglês nas escolas da Prefeitura. Os alunos do $1^{\circ}$ ao $9^{\circ}$ ano têm dois tempos semanais de inglês, com ênfase em comunicação oral. Para reforçar essa estratégia, a Secretaria Municipal de Educação implantou, em 2013, em duas escolas, o ensino bilíngue em Língua Inglesa, com objetivo de introduzir metodologia e práticas de ensino em duas línguas desde a Educação Infantil até o $6^{\circ}$ ano. Em 2014, a SME ampliou o projeto para mais duas escolas que também passaram a oferecer ensino bilíngue em Língua Inglesa e na Escola Municipal Holanda, o ensino bilíngue em Espanhol. No ano de 2015, mais três escolas passaram a oferecer ensino bilíngue em Língua Inglesa. Em 2016, mais duas unidades compõem o grupo de escolas com ensino bilíngue em Língua Inglesa. (http://www.rio.r.j.gov.br/web/sme/exibeconteudo?id=2320722 - Acesso: 5/ago/2017)

O volume em análise não faz parte das coleções elencadas no PNLD para o Ensino Fundamental II. As coleções selecionadas desde 2011 foram:

. 2011 - Keep in Mind (Elizabeth Chin e Maria Lúcia Zaorob - Editora Scipione); Links English for Teens (Amadeus Marques e Denise Santos - Editora Ática);

. 2014 - Alive! (Vera Menezes, Júnia Braga, Claudio Franco - Editora UDP); It fits! (Editor responsável: Wilson Chequi - Editora SM); Vontade de saber inglês (Mariana Killner e Rosana Amâncio - Editora FTD)

. 2017 - Way to English for Brąilian Learner (Claudio Franco e Kátia Tavares - Editora Ática); Team Up (Cristina Mott-Fernandez, Denise Santos, Elaine Hodgson e Reinildes Dias Macmillan Education); It fits! (Ana Luiza Couto - Editora SM); Alive! (Júnia Braga, Vera Menezes - Editora UDP); Time to share (Gisele Aga e Vicente Martínez - Saraiva Educação).

A empresa que fornece os LDs à rede municipal do Rio criou e produziu os livros da coleção. Sendo assim, fizeram o recorte de conteúdo e metodologia que fundamenta a obra. Ela é composta por três unidades que serão analisadas a seguir. O conteúdo indicado para a primeira unidade é a descrição de ações em andamento e no que tange ao que é denominado de Skills for Life (Habilidades para a vida), o item Cultural Plurality (Pluralidade cultural) versa sobre o conhecimento de culturas e hábitos diferentes em outros países. O texto inicial traz o diálogo entre dois adolescentes: Kate, uma jovem negra - ilustrada pela foto de uma jovem bonita, sorrindo; Luiz, um rapaz branco - ilustrado pelo foto de um jovem sorrindo. Ambos parecem pertencer à classe média e conversam sobre seu cotidiano na escola, falando de seus hábitos rotineiros. Na seção de Reading, ainda focando o universo adolescente, o título do texto é Welcome to virtual party! (Bem-vindos à festa virtual!). A ilustração que acompanha o texto apresenta jovens brancos e negros. Em primeiro plano, um casal branco está dançando. Imediatamente após, em segundo plano, há um rapaz louro à esquerda bebendo refrigerante e, à direita, uma jovem cujos traços não definem sua raça/etnia. O que a distingue são a cor de sua pele e os cabelos ondulados. Mais atrás, sentados em um sofá, está um casal de adolescentes negros se beijando. Além da cor da pele, o cabelo indica a etnia/raça. Embora todos sejam retratados como jovens 
em igualdade de condições socioeconômicas e, em quantidade, haja representação equânime de brancos (3) e negros(3), na ilustração os negros não ocupam o primeiro plano.

A atividade dois, que se segue ao texto, traz descrições dos personagens para que o aprendiz escreva o nome daquele a quem a mesma se refere. A menção à raça/etnia ou cor apenas aparece para o personagem Ace (Ace is tall and blond. He's very popular at school and has many friends. Today he is wearing jeans, a T-shirt and sneakers. He's dancing with Tina and they're having lots of fun. [Ace é alto e louro. Ele é muito popular na escola e tem muitos amigos. Hoje ele está vestindo jeans, uma camiseta e tênis. Ele está dançando com Tina e eles estão se divertindo.]) Para os personagens negros as descrições são: Lindy: Lindy is a modern girl. She's sixteen and has long curly hair. Today she is wearing a short skirt, a top, shoes and socks. She loves singing and now she's singing karaoke. [Lindy é uma garota moderna. Ela tem dezesseis anos e longos cabelos ondulados. Hoje ela está vestindo uma mini saia, um top, sapatos e meias. Ela adora cantar e agora está cantando karaokê.]; Rob e Miriel: Rob and Miriel are both 17 years old. They are boyfriend and girlfriend. He's wearing a jacket and pants and she is wearing jeans and a top. They love dancing, but they aren't dancing now. They are sitting on a couch and they are kissing! [Rob e Miriel têm dezessete anos. Eles são namorados. Ele está vestindo uma jaqueta e calças compridas e ela está vestindo jeans e um top. Eles amam dançar, mas não estão dançando agora. Eles estão sentados no sofá e estão se beijando!].

\begin{tabular}{|l|c|c|c|}
\hline Personagem & $\begin{array}{c}\text { Adjetivo para } \\
\text { característica física }\end{array}$ & $\begin{array}{c}\text { Adjetivo para } \\
\text { característica de } \\
\text { personalidade }\end{array}$ & Idade \\
\hline Ace & tall - blond & popular & - \\
\hline Lindy & long curly hair & modern & 16 \\
\hline Miriel & - & - & 17 \\
\hline Rob & - & - & 17 \\
\hline
\end{tabular}

Embora a atividade focalize mais os personagens negros (Lindy, Miriel e Rob) características físicas são atribuídas apenas à Lindy. Da mesma forma, apenas ela tem uma característica de personalidade (positiva) atribuída.

A atividade seis, que provoca a utilização do present progressive, traz 4 ilustrações: [a] um jovem branco toca guitarra; [b] uma jovem branca come hambúrguer; [c] uma jovem branca e uma jovem negra conversam; [d] um jovem negro dança. Embora haja maior representação de brancos [3 personagens] em relação a negros [2 personagens], todos estão em atividades peculiares a adolescentes. Contudo, os personagens negros não ocupam o primeiro plano da ilustração.

Ainda na unidade 1, na atividade 2 da segunda seção de vocabulário, há uma ilustração que toma aproximadamente metade da página de um adolescente - Joshua - ao computador. Pode-se dizer que ele é branco pelos traços que apresenta. Mais adiante, em outra seção de leitura, há uma ilustração de Matt - um jovem negro e Grandma, sua avó que não recebe nome, na sala da casa. O personagem da primeira ilustração e esses são retratados com o mesmo status social. Tanto Matt quanto sua avó foram desenhados com traços suaves, sem caricaturização, 
quase que assemelhados aos traços dos personagens brancos. $\mathrm{Na}$ verdade, isso é frequente nas ilustrações em que personagens femininas negras são retratadas na obra. Essa tendência na ilustração, portanto, reflete a miscigenação da população brasileira.

$\mathrm{Na}$ seção de gramática, que vem em seguida, há uma ilustração de uma família negra. É composta de 6 membros. Em primeiro plano estão a mãe - não tem nome - e Joshua adolescente negro tocando guitarra. Em segundo plano, estão seu irmão menor, Alex, seu avô e sua avó, que não recebem nome. Mais atrás, na cozinha da casa, está o pai preparando a comida. Para essa ilustração, seria relevante ir além da atividade de gramática que leva o aprendiz a escrever cinco frases sobre as pessoas representadas. As perguntas propostas por Bamford (2009) para promover o letramento visual poderiam ser usadas com adaptação. Muitos porquês exploratórios poderiam surgir.

O último texto da unidade 1 é bastante interessante para nossa discussão. $O$ aluno deve ler breves relatos de viagem e numerar a foto da possível pessoa que a redigiu. A primeira ilustração traz duas jovens brancas tomando uma sopa de cobra em um restaurante no Vietnã. Quem escreve se identifica como comissária de bordo e identifica sua amiga pelo nome, Kate. A segunda ilustração traz uma foto que foi tirada por alguém que trabalha para a UNICEF, mas não é retratado. Nela há dois jovens negros do Quênia que vão a pé para a escola. Eles andam dez quilômetros diariamente para terem acesso à educação. O autor do relato elogia os meninos por não reclamarem pelo sacrifício que fazem e diz que todos deveriam aprender a fazer o mesmo. A terceira ilustração é a foto de uma menina negra com idade em torno de 13 anos falando de sua viagem à Escócia. Ela mostra uma foto que tirou com o amigo Carl (adolescente branco, vestindo kilt). Ambos são retratados na ilustração a partir do mesmo status socioeconômico de classe média. Mais uma vez há equilíbrio na quantidade de personagens representando pessoas brancas e negras. Não obstante, o professor em sala de aula com os alunos pode problematizar o fato de haver dois meninos negros indo para a escola sem que lhes seja assegurado o direito ao transporte escolar ou melhores condições de estudar. Parece haver a naturalização da pobreza. É assim e eles lutam contra as adversidades sem reclamar.

Após a última atividade de gramática, há uma foto de uma linda jovem negra, com traços delicados e cabelo não étnico em uma cozinha, possivelmente preparando alguma refeição. Ela está sorrindo, está bem vestida e parece ser a dona da casa. Considerando o conteúdo da unidade (present simple X present progressive) pode ser usada para que os alunos elaborem frases. $\mathrm{Na}$ atividade 7 continua a ênfase no item gramatical da unidade. Há fotos de duas mulheres brancas - uma delas é uma modelo que está comendo um hambúrguer, a outra é uma autora que escreve livros infantis. A primeira está na praia e a segunda em um escritório ao computador ao mesmo tempo em que conversa em um celular. Há também dois homens. O da primeira foto é branco, professor de geografia e está deitado em um sofá, relaxando. O da segunda foto é negro, jogador de futebol. $\mathrm{Na}$ foto, ele é retratado dormindo no campo, tendo a cabeça apoiada na bola de futebol. Mais uma vez há mais pessoas brancas retratadas. Além disso, a profissão do homem negro, jogador de futebol, pode reforçar a ideia que basta ter dom para desenvolver sua atividade profissional, uma vez que não é preciso estudar como o professor de geografia. 
$\mathrm{Na}$ segunda unidade, o conteúdo é a formulação de datas em inglês e algumas datas comemorativas. Em Skills for Life, o item Cultural Plurality versa sobre feriados em diferentes culturas. O texto inicial da unidade tem por título Special dates to note down in your diary (Datas especiais para serem anotadas em sua agenda) e lista as seguintes datas explicando do que se tratam, como surgiram e/ou quando são comemoradas: Valentine's Day (festividade norteamericana, semelhante ao dia dos namorados); Earth Day (dia do planeta Terra); Mother's Day (dia da mães); Father's Day (Dia dos Pais); Thanksgiving (Dia de Ação de Graças, comemorado nos EUA). Na apresentação à coleção e ao volume, em especial, no Teacher's book (Manual do professor) afirma-se que se trabalha com textos semiautênticos provenientes de diferentes esferas e de gêneros diversos. Isso é feito "para que o aluno do Ensino Fundamental 2 seja capaz de fazer uma leitura reflexiva e crítica em língua inglesa” (LAXE; BÜSMAYER, 2012, p. VII) . No caso desse texto, não nos parece que pertença a algum gênero que circule socialmente em contextos outros que o escolar. Nesse texto, há apenas a foto de uma criança branca relacionada ao Dia do Planeta Terra. Para o Dia dos Namorados há a foto de uma caixa de bombom; para o Dia das Mães, flores e uma caixa de presente vermelha e branca; para o Dia dos Pais, uma caixa de presentes com listras azuis; para o Dia de Ação de Graça, um peru assado. As atividades de compreensão que questionam sobre as datas comemorativas às quais as frases se referem ('It is celabrated in June in the USA.' Families usually get together and eat Turkey on These days'. People give gifts on these days.') fazem o aprendiz voltar ao texto e completar as informações em inglês.

Há duas atividades que focalizam festividades brasileiras. A primeira questiona quais das atividades apresentadas também são celebradas no Brasil. A segunda pede ao aluno que escreva quando algumas festividades são celebradas no Brasil. Foram elencadas Mother's Day (dia da mães); Father's Day (Dia dos Pais); Children's Day (Dia das Crianças); Independence Day (dia da Independência); Carnival (Carnaval); Teacher's Day (Dia dos Professores). Não se inclui outros feriados nacionais brasileiros, em especial, dois deles: Abolição da Escravatura e Dia da Consciência Negra. Eles poderiam mobilizar os alunos no sentido de trazerem alguma discussão sobre questões de representação do negro, de pensarem o cotidiano de pessoas negras, de como houve lutas para que as pessoas negras não mais tivessem que viver sob o regime escravocrata. Em uma perspectiva de letramento crítico, conforme Janks (2012), e da Prática Exploratória (MILLER, 2013; MORAES BEZERRA, 2015) caberia o planejamento de uma APPE no sentido de se questionar, por exemplo, 'Por que apenas datas comemorativas características dos Estados Unidos aparecem no texto que inicia a unidade?" Talvez houvesse questionamentos sobre as ausências, a invisibilização dos feriados acima mencionados. Os alunos poderiam ser encorajados a pesquisar como tais datas surgiram em diferentes livros de história, comparando a forma como as mobilizações para a libertação dos escravos aconteceu, a luta dos quilombolas, o que aconteceu no pós abolição, as lutas contemporâneas dos movimentos negros. Possíveis ligações poderiam ser feitas com o segundo feriado - Dia da Consciência Negra. 'Por que surgiu?' 'Por que ainda é necessário fazer tal mobilização?' Eles poderiam produzir pôsteres para partilhar com os colegas seus entendimentos ou usar outros gêneros para trazer suas questões como os alunos de Moraes Bezerra (2015) fizeram ao produzirem capas de revistas e usando a 
língua inglesa para escrever questões que os mobilizavam. Foi um processo de escrita situada, colaborativa e profundamente reflexiva.

$\mathrm{Na}$ seção de Reading (Leitura), o texto selecionado traz informações sobre a comemoração do ano novo em Barcelona (Espanha), Edimburgo (Escócia) e Beijing (China). A atividade 5 que se segue ao texto, novamente provoca uma comparação com o Brasil. Nessa atividade, há a foto de uma jovem branca e loura que afirma "I love New Year in Rio de Janeiro". Nesse exercício ainda há uma forma reducionista de descrever como brasileiros celebram essa data. Já na atividade 6, os alunos dão respostas pessoais a como celebram a data. Em uma perspectiva de letramento crítico e do 'envolver todos para desenvolvimento mútuo' da Prática Exploratória, os alunos poderiam ser encorajados a recriar a atividade de forma a abarcar outras formas de comemoração, talvez apontando para a forma como fiéis de religiões de matriz africana fazem seus rituais para a celebração do novo ano.

Nessa unidade, não há o foco multicultural prometido, uma vez que a cultura negra americana não tem lugar, sendo ratificada a cultura branca hegemônica. Nem mesmo quando se traz o Brasil, a Espanha, a Escócia e a China, isso é feito de maneira breve, ainda mantendo a ideia de que as cidades mencionadas metonimicamente são a parte representando o todo, i.e., o país. O aspecto multicultural e étnico não aparece verdadeiramente.

O conteúdo da terceira unidade é voltado para situações em restaurantes, para fazer e recusar ofertas no que se refere a alimentos e refeições, além de tratar de alimentação saudável. No âmbito do item Cultural Plurality, aponta-se que o foco recai em aprender sobre a hora do café da manhã em diferentes culturas. Há uma ilustração iniciando a unidade. Nela podem ser vistos um casal de pessoas brancas brindando, um garçom branco servindo um cliente negro, um astronauta negro entrando, além de dois extraterrestres (mãe e filho). Pode-se dizer que, excetuando-se os extraterrestres, todos, brancos e negros, são retratados esteticamente de forma positiva, com os negros apresentando cor de pele e cabelo compatíveis. Não estão em situação de subalternidade e um deles, o cliente, ocupa o primeiro plano da ilustração ao lado do garçom. O foco da atividade é o trabalho com vocabulário relevante para a temática da lição e para o texto que vem a seguir que discute alimentação no espaço.

No que diz respeito a fotos e ilustrações, talvez pelo conteúdo da unidade, muitos alimentos são retratados. Além da ilustração inicial descrita acima, encontramos a foto de um sushiman, a ilustração de uma jovem branca tomando seu café da manhã, uma tirinha com personagens brancos e uma ilustração de um casal de jovens que parecem ser latinos. Dessa forma, na contagem geral de personagens na unidade, há dois negros apenas retratados em iguais condições em relação aos outros personagens da cena.

Ao final dessa análise, assim como outros pesquisadores, pensamos que já é possível mapear mudanças significativas na representação visual de pessoas negras, ao menos nesse livro didático. Contudo, sentimos a ausência de textos que provoquem leituras sobre a condição social dessas pessoas, sobre suas lutas. $\mathrm{Na}$ verdade, o livro didático analisado ainda segue o padrão editorial e não problematiza a vida social, mas ele não é o único. E isso é provocador, pois nos leva a outros movimentos reflexivos. 


\section{REVENDO A REFLEXÃO}

Nesse artigo trabalhamos para construir e partilhar uma possibilidade de abordagem não fechada e acabada de ensino a partir do diálogo entre Prática Exploratória, letramento crítico e letramento visual. No que concerne ao foco de nossa reflexão - a representação de pessoas negras em um livro didático - o que nos mobilizou não foi apenas discutir mais um proposta para o ensino de LE, mas também as implicações de práticas pedagógicas para a construção identitárias dos envolvidos nas práticas discursivas escolares. A partir de tudo que apresentamos esperamos ter trazido alguma contribuição para a área e, ao mesmo tempo, desejamos encorajar outros pesquisadores a pensarem em alternativas para que o ensino de LE seja relevante para a vida dos aprendizes e contribua para pensar sobre formas de usar o discurso e as imagens para redesenhar a vida social, para construir sociabilidades mais fraternas e plurais.

\section{REFERÊNCIAS:}

ALLWRIGHT, D.; HANKS, J. The Developing Language Learner - An introduction do Exploratory Practice. London: Palgrave Macmillan, 2009.

BAMFORD, A. The visual literacy white paper. 2009. Disponível em: http://www.adobe.com/uk/education/pdf/adobe visual literacy paper.pdf

BRASIL. Ministério da Educação. Programa Nacional do Livro Didático: histórico e perspectivas. Brasília, MEC, 2000.

CRUZ, M. Prática Exploratória: a importância dos “porquês”. Educação Pública, 2007. Disponível em: http://www.educacaopublica.rj.gov.br/jornal/materias/0377.html

FERREIRA, A. de J. Identidades sociais de raça, gênero, sexualidade e classe nos livros didáticos de língua estrangeira na perspectiva da linguística aplicada. In FERREIRA, A. de J. As políticas do livro didático e identidades sociais de raça, gênero, sexualidade e classe em livros didáticos. Campinas: Pontes, 2014.

FERREIRA, A. de J. Identidades sociais: letramento visual e letramento crítico: imagens na mídia acerca de raça e etnia. Trabalhos em Linguística Aplicada, Campinas, n.(51.1), 2012.

Disponível em: $\quad$ http://www.scielo.br/scielo.php? script=sci arttext\&pid=S0103$\underline{18132012000100010}$

FERREIRA, A. de J.; CAMARGO, M. O racismo cordial no livro didático de língua inglesa aprovado pelo PNLD. Revista da ABPN, v.6, n.12, nov.2013. Disponível em: http://abpnrevista.org.br/revista/index.php/revistaabpn1/article/view/182

JANKS, H. The importance of critical literacy. English Teaching: Practice and Critique. Vol. 11, n.1, 2012. Disponível em: http://files.eric.ed.gov/fulltext/EJ970245.pdf 
JORGE, M. L dos S. Livros didáticos de língua estrangeiras: construindo identidades positivas. In: FERREIRA, A. de J. (Org.) As políticas do livro didático e identidades sociais de raça, gênero, sexualidade e classe em livros didáticos. Campinas: Pontes Editores, 2014.

KUBOTA, R. Critical multiculturalism and second language education. In. NORTON, B.; TOOHEY, K. (Ed.) Critical pedagogies and language learning. Cambridge University Press, 2004.

LANKSHEAR, C. Changing literacies. Buckingham: Open University Press, 2002.

LAXE, L.; BÜSMAYER, S. Interaction ED 4. Rio de Janeiro: Learning Factory, 2012.

MILLER, I. K. Formação de professores de línguas: da eficiência à reflexão crítica e reflexiva. In: MOITA LOPES, L. P. (Org.) Linguística Aplicada na Modernidade Recente. São Paulo: Parábola, 2013.

MILLER, I. K. Construindo parcerias universidade-escola: caminhos éticos e questões críticoreflexivas. In: GIMENEZ, T.; MONTEIRO, M. C. de G. (Orgs.) Formação de professores de Linguas na América Latina e Transformação Social. Campinas: Pontes Editores, 2010.

MOITA LOPES, L. P. Socioconstrucionismo: discurso e identidade social. In: MOITA LOPES, L. P. Discursos de Identidades: discurso como espaço de construção de gênero, sexualidade, raça, idade e profissão na escola e na familia. Campinas: Mercado de Letras, 2003.

MORAES BEZERRA, I. C. R. Gêneros discursivos, ensino de língua estrangeira e prática docente: a vida em capas de revistas. In: MORAIS, J de F.; WILSON, V. (Orgs.) Leitura, escrita e ensino: discutindo a formação de leitores. São Paulo: Summus, 2015.

NEGRÃO, E. V. Preconceitos e discriminações raciais em livros didáticos infanto-juvenis. Cadernos de Pesquisa. Fundação Carlos Chagas, maio/1988.Disponível em: http://publicacoes.fcc.org.br/ojs/index.php/cp/article/view/1196

TEIDER, D. A.; FERREIRA, A. de J. Identidades sociais - raça e etnia, análise da imagem do negro no livro didático de língua estrangeira. Anais $3^{\circ}$ Congresso Internacional de Educação. ISAPG, 2011. Disponível em: http://www.isapg.com.br/2011/ciepg/selecionados.php

ORIÁ, R. O negro na historiografia didática: imagens, identidade e representações. T.E.X.T.O.S de H.I.S.T.Ó.R.I.A. v.4, n.2, 1996.1 Disponível em: http://periodicos.unb.br/index.php/textos/article/view/5790/4798

PARKER, I. Discourse and Power. In: SHOTTER, J.; GERGEN, K. J. (Eds.) Texts of identity. London: SAGE, 1989.

PINTO, R. P. A representação do negro em livros didáticos de leitura. Cadernos de Pesquisa. Fundação Carlos Chagas, nov./1987. Disponível em: http://publicacoes.fcc.org.br/ojs/index.php/cp/article/view/1280

RATTS, A. J. P.; RODRIGUES, A. P. C.; VILELA, B. P.; CIRQUEIRA, D. M. Representações da África e da população negra nos livros didáticos de geografia. Revista da Casa da Geografia de Sobral, v.8/9, n.1, 2006/2007. Disponível em: 
https://www.academia.edu/1836201/Representa $\%$ C3\%A7\%C3\%B5es da \%C3\%81frica e da popula $\% \mathrm{C} 3 \% \mathrm{~A} 7 \% \mathrm{C} 3 \% \mathrm{~A} 3 \mathrm{o}$ negra nos livros did $\% \mathrm{C} 3 \% \mathrm{~A} 1$ ticos de Geografia

ROSEMBERG, F.; BASILLI, C; SILVA, P.V.B. Racismo em livros didáticos brasileiros e seu combate: uma revisão da literatura. Educação e Pesquisa, São Paulo, v.29, jan.//jun. 2003.Disponível em: $\quad$ http://www.scielo.br/scielo.php?script=sci arttext\&pid=S1517$\underline{97022003000100010}$

SANTOS, K. de O. As relações étnico-raciais no livros didático da educaşão de jovens e adultos : implicações curriculares para uma sociedade multicultural. Dissertação de Mestrado. Programa de Pós-graduação em Educação. Mestrado em Educação Brasileira. Universidade Federal de Alagoas, 2011.Disponível em: http://www.repositorio.ufal.br/handle/riufal/363

SHOTTER, J. Social accountability and the social construction of 'you'. In: SHOTTER, J.; GERGEN, K. J. (Eds.) Texts of identity. London: SAGE, 1989. 